\title{
COPING BEHAVIOUR AS THE WAY TO OVERCOME STRESS OF SPECIALISTS OF FIRE AND RESCUE UNITS OF THE STATE EMERGENCY SERVICE OF UKRAINE
}

\author{
Mokhnar L. I., PhD in Pedagogy, assistant professor of Department of Psychological Activity in \\ Special Conditions, Cherkasy Institute of Fire Safety named after Chornobyl Heroes of the National \\ University of Civil Defence of Ukraine \\ Diachkova O. M., PhD in Pedagogy, assistant professor of Department of Psychological Activity in \\ Special Conditions, Cherkasy Institute of Fire Safety named after Chornobyl Heroes of the National \\ University of Civil Defence of Ukraine
}

\section{DOI: https://doi.org/10.31435/rsglobal_conf/25022021/7420}

Abstract. The concept and the types of coping and coping strategies are defined in the article. The characteristics of coping strategies are also analyzed. The peculiarities of professional activity of specialists of fire and rescue units of the State Emergency Service are specified and the main types of stressful situations in their professional activity are presented.

Keywords: stress, stressors, stressful situations, coping, coping strategies.

Introduction. The professional activity of specialists of fire and rescue units of the State Emergency Service of Ukraine is characterized by an increased level of complexity and risk. Almost always specialists are in a state of stress because of the need of being always ready to perform activities in unpredictable conditions. In addition, firefighter-rescuers suffer from stressors of the professional activity. This impact can be strong and one-time, as well as intense and returnable (while on duty in emergency). So, the professional activity efficiency of specialists of fire and rescue units of the State Emergency Service of Ukraine in difficult, stressful and extreme situations is determined by the formation of the necessary strategies for coping behaviour.

A review of the literature. The theoretical foundations of the problem of coping behaviour are closely connected with the problem of stress. Coping and stress are two inseparable processes for a person.

Works devoted to the study of ways to overcome stress or coping, appeared in foreign psychology in the second half of XX-th century. The term "coping" comes from the English "to cope". The term "bewaltigung" is used in the works of German authors. Coping - an individual way of interacting with the situation in accordance with its personal logic, significance in human life and its psychological possibilities.

The first psychological studies of coping as a person's behaviour in the conditions of overcoming the difficult life situations were conducted in the second half of the XX-th century. The term "coping" was firstly used by L. Murphy, who studied the overcoming of developmental crises of children - the active efforts of the individual which are aimed to cope with a difficult situation or a problem. The term "coping" (from English - to overcome; to withstand, to get through), was introduced by the researcher to denote the desire of the individual to solve a certain problem [3]. In the future, the problem of coping continued to be developed in the context of studying stress and processes oriented to overcome the stressful situations of so-called coping behaviour.

According to A. Maslow, coping is an individual's willingness to solve life's problems by adapting to the circumstances, which involves the formation of the ability to use certain devices to overcome stress. If you choose the active forms of behaviour, the probability of removal the impact of stressors on the individual increases. Features of this skill are associated with "Self-identity", the locus of control, empathy, environmental conditions [2].

In the works of national psychologists, we find the determination of the concept of "coping" as the overcoming (stress management) or psychological coping with stress. Defining the overcoming behaviour contains a number of problems, the solution of which reveals different conceptual approaches and interpretations of the researched phenomenon.

Trying to create a coherent classification of copings, researchers identify several levels of generalization of what an individual does to overcome stress: coping actions, coping strategies, coping styles, coping behaviour. 
Coping actions (what an individual feels, thinks or does) are often grouped into coping strategies - stress management tools that appear as a person's response to a perceived threat. The strategies, in turn, are grouped into coping styles. Sometimes the terms "coping actions" and "coping strategies" are used interchangeably, while coping styles refer to actions or strategies that are consistently used by an individual to overcome stress. So, to overcome stress, each person uses his/her own strategies (coping strategies) based on personal experience and psychological reserves - coping resources - relatively stable characteristics of people and stress, which contribute to the development of means to overcome it [4].

Presentation of the main material. Presently, there are three types of coping:

1. coping, aimed to evaluate (considered as overcoming stress, which includes attempts to determine the significance of the situation and put into action the strategy - logical analysis, cognitive reassessment, etc.);

2. coping, aimed to the problem (considered as a process of stress management, which aims to modify, reduce or eliminate the source of stress);

3. coping, oriented on emotions (defined as overcoming stress, which includes cognitive, behavioral efforts by which the individual tries to reduce emotional stress).

In general, the scientists and experts consider the basic coping strategies to be the strategies of "problem solving", "seeking social support" and "avoidance". The researches give the basic coping strategies such characteristics:

1. Problem-solving strategy is an active behavioural strategy, using of which the person tries to use personal resources to find possible ways to effectively solve the problem.

2. The strategy of finding the social support is an active behavioural strategy, using of which the person seeks help and support from the environment: family, friends with the aim to solve the problem in proper way.

3. Evasive strategy is a behavioural strategy, using of which, a person tries to avoid contact with the outside world, displaces the need to solve the problem. Methods of avoidance include escape to the disease, increased alcohol and drug use, a variant of the active method of avoidance - suicide. Avoidance strategy is one of the leading behavioural strategies that contributes to the formation of maladaptive, pseudo-overcoming behaviour. The use of this strategy is characterized by the insufficient level of personal coping resources and skills of active solving of life problems. The avoidance strategy may be adequate or inadequate depending on the specific stressful situation, age and condition of the resource system of the individual [5].

The most effective is the situational use of all three behavioural strategies.

It is known that in the professional activity of specialists of fire and rescue units of the State Emergency Service of Ukraine there are 4 main types of stressful situations [1].

The first type of situations is associated with the constant daily activity of specialists of fire and rescue units of the State Emergency Service of Ukraine and is characterized by the conditions to which the specialist is accustomed, i. e. he knows how, when and what to do, he has a set of usual types of behaviour in such situations. These situations do not pose a threat to the firefighter-rescuer; in any case, they are so assessed by him.

Situations of the second type are characterized by a violation of the parameters of habit, standard behaviour in general or in any particular action. These situations, as well as the first, do not pose a threat to the life and health of the specialist of the fire and rescue unit of the State Emergency Service of Ukraine.

Situations of the third type differ from the situations of the first type by the presence of elements of danger and risk, however, activity in such situations is carried out according to known rules and standards (for example, a firefighter eliminates a fire - the action is dangerous but familiar).

Finally, situations of the fourth type take place in the conditions of danger and risk, as well as complete or almost complete ignorance of the algorithms of the activity to achieve the target goal (for example, a firefighter must be involved in a large-scale emergency).

The behaviour of specialists of fire and rescue units of the State Emergency Service of Ukraine according to the impact of the situation of any type can be [1]:

1) adaptive (adequate to the situation and aimed at solving the problems caused by this situation);

2) pseudo-adaptive (imitating activity, but not achieving the goal or only partially achieving);

3) maladaptive (evading the solving of problem). 
The basic scheme of response to stressors in coping behaviour includes cognitive assessments (primary and secondary), as well as emotional-evaluation reactions. The initial assessment of the stressor firstly ascribes to it a certain sign, i. e. the stressor (event) is assessed either as positive (good), or as negative (harmful, dangerous, etc.) or as neutral. Then, based on the initial cognitive assessment of the event, there is an unconscious inclusion of emotional and evaluative reactions, which are controlled by cognitive assessment. After the inclusion of emotional assessment, a certain controlled mental state is formed (in the conditions of which the corresponding behaviour takes place). The third stage of stress response involves secondary cognitive assessment, which by the mechanism of feedback or approves the initial assessment and activity based on it (with some possible adjustment of mental state and behaviour), or if the activity and mental state are assessed as incorrect, performs the functions of psychological protection.

To overcome stress, each specialist uses their own strategies (coping strategies) based on the subjective experience (personal resources or coping resources). Therefore, the stress-coping behaviour is considered by most scientists today as a result of the interaction of coping resources and coping strategies of the individual.

Conclusions. The specialists of the State Emergency Service with different work experience, in different stressful situations, with different level of psychosomatic health of coping strategies have their own peculiarities of development. In some cases, the State Emergency Service specialist can overcome the difficulties on his own, in other cases he needs the support of others, sometimes - he can simply avoid facing with the problem, determining in advance the negative consequences of such problem.

\section{REFERENCES}

1. Nazarov O. O., Onishchenko N. V., Sadkovyi V. P., Sadkovyi O. V., Sklen O. I., Timchenko O. V. The psychological features of basic coping strategies and personal coping resources of specialists of fire and rescue units of the Ministry of Emergencies of Ukraine: Monograph. - Kh.: Publishing company National University of Civil Defence of Ukraine, 2008. - 184 p.

2. Onishchenko N. V., Sklen O. I. Gender aspect of coping behaviour // Proceedings of the scientific-practical conference: actual problems of supervisory and preventive activity of the Ministry of Emergencies of Ukraine. - Kharkiv: National University of Civil Defence of Ukraine, 2007. - P. 141-142.

3. Rodina N. V. Psychology of coping behavior: system modeling [Text]: thesis ... Ph. D. in Psychology: 19.00.01 / Rodina Nataliia Volodymyrivna; Kyiv National University named after Taras Shevchenko. - K., 2012. - 504 p.

4. Rodina N. V. To the problem of the relationship between the concepts of "coping strategies" and "protection mechanisms". Psychodynamic approach. / Materials of the All-Ukrainian scientific-practical conference "Ways of the development of psychology in Ukraine: history and modernity." - K.: Lybid, 2006. - P. 98-104.

5. Sklen O. I. Basic strategies of coping behavior of specialists of emergency rescue units of the Ministry of Emergencies of Ukraine, dynamics and features of their change in various stressful situations // Scientific notes of the Institute of Psychology named after G. S. Kostiuk of Academy of Pedagogical Sciences of Ukraine / Ed. academician S. D. Maksymenko. - K .: Millennium, 2006. - Issue 27. - P. 476 - 486. 